\title{
Biochemical and Technological Properties of Rosa Canina L. Fruits from Spontaneous Flora of Oltenia, Romania
}

\author{
Rodica SOARE ${ }^{1 *}$, Dorina BONEA ${ }^{1)}$, Paula IANCU ${ }^{1)}$, Mariana NICULESCU ${ }^{1)}$ \\ 1) Faculty of Agriculture and Horticulture, University of Craiova, Romania \\ ${ }^{*}$ Corresponding author, e-mail: soarerodi@yahoo.com
}

BulletinUASVM Horticulture 72(1) / 2015

Print ISSN 1843-5254, Electronic ISSN 1843-5394

DOI:10.15835/buasvmen-hort:10598

\begin{abstract}
Rosa canina (wild rose, bush, bramble, dog rose, rosehip) is a shrub commonly encountered in the wild flora of Romania, spread from the coast up to altitudes of $1200 \mathrm{~m} \mathrm{(1700),} \mathrm{with} \mathrm{low} \mathrm{requirements} \mathrm{to} \mathrm{pedoclimatic} \mathrm{factors.}$ From this species are used the false-fruits (Cynosbati fructus) mature, dried, harvested from wild flora or cultures, with food and therapeutic importance, due to their multiple properties, but mostly because of its high content of vitamin C. In this way, it were studied the germoplasm sources existent in some areas of Oltenia (Romania) to identify valuable biotypes from biochemically and technologically point of view. The results indicate a high and very high variability of the analyzed parameters. Thus, the content of TSS was recorded between 10\% (B2) and $18 \%$ (M1), vitamin C varied from $53 \mathrm{mg} / 100 \mathrm{~g}$ (B3) to $563 \mathrm{mg} / 100 \mathrm{~g}$ to populations (S1, S3) and acidity from $1.4 \%$ (B3) to 3.6\% (M4). Recorded values for the mass of 100 fruit, between $117 \mathrm{~g}$ (A1) and 286g (B3 and T4) and the percentage of pulp/100g fruit ranged from 49.2 (M1) and 66.5 (T1).
\end{abstract}

Keywords: biodiversity, rosehips fruits, vitamin $C$

\section{INTRODUCTION}

Rosa canina is a spontaneous species with multiple uses. It has been used as a rootstock for ornamental roses (Wagner, 2002; Nețoiu et al., 2008; Shirdel et al., 2013). Also it is one of the important medicinal (Kazaz et al., 2009; Sharafi, 2010) and food plants (Kaack and Kuhn, 1991; Özcan, 2002; Șerban, 2011). In terms of the food, rosehip fruit can serve as raw material to obtain the paste, jam, marmalade for dessert soup, wine, juices, etc. (Kaack and Kuhn, 1991; Wagner, 2002; Güneș, 2010). In Hungary, rosehip fruits are used in the manufacture of brandy, in Danish markets are available the powder of dried rosehip fruit and in Sweden, the fruits are used especially in commercial soups (Gaik, 2011).

Rosehip, it can be used to prevent soil erosion and as shelterbelts or defensive fence (Nețoiu et al., 2008). Some authors said that Rosa canina fruits are rich in vitamin $\mathrm{C}$ and presents benefic effect on human health (Haas, 1995; Demir and Özcan, 2001; Mabellini et al., 2011; Roman et al., 2013).

Rosehip fruits also contain minerals: $\mathrm{P}, \mathrm{K}, \mathrm{Ca}$, $\mathrm{Fe}, \mathrm{Cu} . \mathrm{Mn}, \mathrm{Zn}, \mathrm{Na}, \mathrm{B}$, flavonoids and carotenoids such as lycopene, the pigment that gives the redorange (Demir and Özcan, 2001; Kazaz et al., 2009), polyphenols (Roman et al., 2013). The oil of dog rose seed contains fatty acids like oleic, linoleic, palmitic, stearic, and arachidonic (Özcan, 2002; Kazaz et al., 2009).

A key priority in the global human diet is the orientation towards organic products derived from this species. By establishing ecological plantations of Rosa canina, production can be used as raw material contributing to the development of processors for organic products.

In other countries, rosehip is cultivated from a long time, but in Romania, recently began to setting up experimental plantations realised with 
hybrid not from varieties of wild flora (Roman and Holonec, 2012).

The aim of the study is to identify some valuable genotypes from biochemical and technological point of view, from spontaneous flora sites existing in Oltenia area.

\section{MATERIALS AND METHODS}

For the study, were harvested in 2013, rosehip fruits from 24 local populations, existing in Dolj and Olt county, especially in the areas not worked for a period of over 10 years. Analyzed biotypes became from areas rich in Rosa canina clumps of villages: Carcea (Banu Maracine), Simnic, Morunglav, Teslui and Argetoaia. The altitude ranged from $148 \mathrm{~m}$ to $191 \mathrm{~m}$

Within these populations was followed the variability of some technological parameters: fruit length, fruit diameter and fruit weight. For the analyzes, 100 rosehip fruit samples were

Tab. 1. Values of some statistical parameters for fruits length

\begin{tabular}{|c|c|c|c|c|}
\hline No. & $\begin{array}{c}\text { Population/ } \\
\text { County }\end{array}$ & $\mathrm{X} \pm \mathrm{S}_{\mathrm{x}}$ & s & $\mathrm{S} \%$ \\
\hline \multicolumn{5}{|c|}{ Carcea (Banu Maracine)-Dolj } \\
\hline 1 & B1 & $2.04 \pm 0.070$ & 0.222 & 10.88 \\
\hline 2 & B2 & $2.49 \pm 0.133$ & 0.422 & 16.98 \\
\hline 3 & B3 & $2.88 \pm 0.127$ & 0.402 & 13.96 \\
\hline 4 & B4 & $1.63 \pm 0.057$ & 0.182 & 11.21 \\
\hline 5 & $\mathrm{~B} 5$ & $2.36 \pm 0.080$ & 0.254 & 10.79 \\
\hline \multicolumn{5}{|c|}{ Simnic-Dolj } \\
\hline 6 & S1 & $2.36 \pm 0.060$ & 0.189 & 8.03 \\
\hline 7 & S2 & $2.44 \pm 0.115$ & 0.365 & 14.99 \\
\hline 8 & S3 & $2.18 \pm 0.053$ & 0.168 & 7.73 \\
\hline 9 & S4 & $2.45 \pm 0.089$ & 0.283 & 11.58 \\
\hline 10 & S5 & $2.33 \pm 0.039$ & 0.125 & 5.37 \\
\hline 11 & S6 & $2.38 \pm 0.098$ & 0.311 & 13.10 \\
\hline 12 & S7 & $1.83 \pm 0.059$ & 0.188 & 10.32 \\
\hline \multicolumn{5}{|c|}{ Morunglav-Olt } \\
\hline 13 & M1 & $1.56 \pm 0.068$ & 0.217 & 13.91 \\
\hline 14 & M2 & $2.13 \pm 0.115$ & 0.365 & 17.15 \\
\hline 15 & M3 & $2.0 \pm 0.105$ & 0.333 & 16.66 \\
\hline 16 & M4 & $1.83 \pm 0.090$ & 0.286 & 15.67 \\
\hline 17 & M5 & $1.99 \pm 0.054$ & 0.172 & 8.68 \\
\hline \multicolumn{5}{|c|}{ Teslui - Olt } \\
\hline 18 & $\mathrm{~T} 1$ & $2.36 \pm 0.063$ & 0.201 & 8.52 \\
\hline 19 & $\mathrm{~T} 2$ & $2.31 \pm 0.070$ & 0.223 & 9.66 \\
\hline 20 & T3 & $2.11 \pm 0.052$ & 0.166 & 7.88 \\
\hline 21 & $\mathrm{~T} 4$ & $2.46 \pm 0.099$ & 0.313 & 12.74 \\
\hline \multicolumn{5}{|c|}{ Argetoaia-Dolj } \\
\hline 22 & A1 & $1.42 \pm 0.068$ & 0.214 & 15.14 \\
\hline 23 & A2 & $1.45 \pm 0.070$ & 0.222 & 15.33 \\
\hline 24 & A3 & $1.37 \pm 0.080$ & 0.254 & 18.54 \\
\hline
\end{tabular}

formed and the results were statistically analyzed calculating the arithmetic mean, standard deviation and coefficient of variance (Botu and Botu, 2010). Percentage of pulp was reported to $100 \mathrm{~g}$ fresh fruit. To determine the biochemical content were analyzed: TSS, vitamin C and acidity. The content of soluble dry substance (TSS) was determined with Abbe refractometer, titratable acidity was determined with $0.1 \mathrm{~N} \mathrm{NaOH}$ in the presence of phenolphthalein as indicator and vitamin $\mathrm{C}$ was determined by iodometric method.

\section{RESULTS AND DISCUSSIONS}

Rosehip fruits length is a character with high variability. In the populations studied this character recorded a magnitude of variation ranging between $1.42 \mathrm{~cm} \mathrm{(A1)} \mathrm{and} 2.49 \mathrm{~cm}$ (B2). Regarding the coefficient of variation, it was between 5.37 and $18.54 \%$, indicating variability from small to medium (Tab. 1).

Tab. 2. Values of some statistical parameters for fruits diameter $(\mathrm{cm})$

\begin{tabular}{|c|c|c|c|c|}
\hline No. & $\begin{array}{c}\text { Population/ } \\
\text { County }\end{array}$ & $\mathrm{X} \pm \mathrm{S}_{\mathrm{x}}$ & $S$ & S\% \\
\hline \multicolumn{5}{|c|}{ Carcea (Banu Maracine)-Dolj } \\
\hline 1 & $\mathrm{~B} 1$ & $1.35 \pm 0.103$ & 0.327 & 24.25 \\
\hline 2 & B2 & $1.18 \pm 0.035$ & 0.113 & 9.62 \\
\hline 3 & B3 & $1.38 \pm 0.092$ & 0.293 & 21.27 \\
\hline 4 & B4 & $1.17 \pm 0.061$ & 0.194 & 16.63 \\
\hline 5 & B5 & $1.22 \pm 0.038$ & 0.122 & 10.07 \\
\hline \multicolumn{5}{|c|}{ Șimnic-Dolj } \\
\hline 6 & S1 & $1.33 \pm 0.030$ & 0.094 & 7.13 \\
\hline 7 & $\mathrm{~S} 2$ & $1.3 \pm 0.039$ & 0.124 & 9.59 \\
\hline 8 & S3 & $1.3 \pm 0.042$ & 0.133 & 10.25 \\
\hline 9 & S4 & $1.35 \pm 0.082$ & 0.259 & 19.20 \\
\hline 10 & S5 & $1.34 \pm 0.049$ & 0.157 & 11.77 \\
\hline 11 & S6 & $1.29 \pm 0.034$ & 0.110 & 8.53 \\
\hline 12 & S7 & $1.43 \pm 0.068$ & 0.216 & 15.12 \\
\hline \multicolumn{5}{|c|}{ Morunglav-Olt } \\
\hline 13 & M1 & $1.03 \pm 0.030$ & 0.094 & 9.21 \\
\hline 14 & M2 & $1.14 \pm 0.049$ & 0.157 & 13.83 \\
\hline 15 & M3 & $0.96 \pm 0.040$ & 0.126 & 13.17 \\
\hline 16 & M4 & $0.91 \pm 0.043$ & 0.137 & 15.05 \\
\hline 17 & M5 & $1.05 \pm 0.054$ & 0.171 & 16.34 \\
\hline \multicolumn{5}{|c|}{ Teslui-Olt } \\
\hline 18 & $\mathrm{~T} 1$ & $1.33 \pm 0.039$ & 0.125 & 9.41 \\
\hline 19 & $\mathrm{~T} 2$ & $1.23 \pm 0.047$ & 0.149 & 12.14 \\
\hline 20 & T3 & $1.33 \pm 0.065$ & 0.205 & 15.46 \\
\hline 21 & $\mathrm{~T} 4$ & $1.44 \pm 0.070$ & 0.222 & 15.42 \\
\hline \multicolumn{5}{|c|}{ Argetoaia-Dolj } \\
\hline 22 & A1 & $1.18 \pm 0.046$ & 0.147 & 12.50 \\
\hline 23 & $\mathrm{~A} 2$ & $1.19 \pm 0.064$ & 0.202 & 17.01 \\
\hline 24 & A3 & $1.31 \pm 0.070$ & 0.223 & 17.05 \\
\hline
\end{tabular}


Other works indicate values between 1.2 to $4.6 \mathrm{~cm}$ for some populations of wild flora in Transylvania (Roman et al, 2013), between 18.5 to $24.75 \mathrm{~mm}$ for wild flora of Moldova (Ghiorghiță et al., 2012) and between 1.43 to $3.02 \mathrm{~cm}$ for some populations of wild flora Oltenia (Sun et al., 2014) and the foreign literature (Van region of Turkey) are given values between 15.28 -33, 83 mm (Celik et al., 2009).

In the populations studied, fruits diameter ranged between $0.91 \mathrm{~cm} \mathrm{(M4)} \mathrm{and} 1.44 \mathrm{~cm}$ (T4), with a coefficient of variation low to high, respectively, from $7.13 \%$ to $24.25 \%$ (Tab. 2).

In other works are given values between 0.95 to $1.51 \mathrm{~cm}$ (Soare et al., 2014), $11.86 \mathrm{~mm}, 16.80$ mm (Ghiorghiță et al., 2012) and from 13.11 to $19.26 \mathrm{~mm}$ (Celik et al., 2009).

Another important morphological character for productivity is the weight of the fruits. This character recorded values between $1.06 \mathrm{~g}$ (A1)

Tab. 3. Values of some statistical parameters for fruits weight

\begin{tabular}{|c|c|c|c|c|}
\hline No. & $\begin{array}{c}\text { Population/ } \\
\text { County }\end{array}$ & $\mathrm{X} \pm \mathrm{s}_{\mathrm{x}}$ & s & $\mathrm{S} \%$ \\
\hline \multicolumn{5}{|c|}{ Carcea (Banu Maracine)-Dolj } \\
\hline 1 & B1 & $1.90 \pm 0.251$ & 0.795 & 41.87 \\
\hline 2 & B2 & $1.54 \pm 0.141$ & 0.447 & 29.02 \\
\hline 3 & B3 & $2.71 \pm 0.252$ & 0.796 & 29.39 \\
\hline 4 & B4 & $1.19 \pm 0.128$ & 0.405 & 34.17 \\
\hline 5 & B5 & $2.17 \pm 0.148$ & 0.470 & 21.69 \\
\hline \multicolumn{5}{|c|}{ Șimnic-Dolj } \\
\hline 6 & $\mathrm{~S} 1$ & $2.42 \pm 0.085$ & 0.270 & 11.18 \\
\hline 7 & $\mathrm{~S} 2$ & $2.37 \pm 0.147$ & 0.465 & 19.62 \\
\hline 8 & S3 & $2.37 \pm 0.101$ & 0.322 & 13.61 \\
\hline 9 & S4 & $2.74 \pm 0.209$ & 0.662 & 24.18 \\
\hline 10 & S5 & $2.63 \pm 0.141$ & 0.445 & 16.92 \\
\hline 11 & S6 & $2.07 \pm 0.132$ & 0.417 & 20.20 \\
\hline 12 & S7 & $2.02 \pm 0.157$ & 0.497 & 24.60 \\
\hline \multicolumn{5}{|c|}{ Morunglav-Olt } \\
\hline 13 & M1 & $1.36 \pm 0.082$ & 0.260 & 19.18 \\
\hline 14 & M2 & $1.94 \pm 0.130$ & 0.412 & 21.25 \\
\hline 15 & M3 & $1.26 \pm 0.121$ & 0.382 & 30.25 \\
\hline 16 & M4 & $1.40 \pm 0.111$ & 0.350 & 25.12 \\
\hline 17 & M5 & $1.67 \pm 0.144$ & 0.457 & 27.6 \\
\hline \multicolumn{5}{|c|}{ Teslui -Olt } \\
\hline 18 & $\mathrm{~T} 1$ & $2.40 \pm 0.075$ & 0.240 & 9.98 \\
\hline 19 & $\mathrm{~T} 2$ & $2.23 \pm 0.147$ & 0.464 & 20.83 \\
\hline 20 & T3 & $2.29 \pm 0.167$ & 0.530 & 23.16 \\
\hline 21 & $\mathrm{~T} 4$ & $2.92 \pm 0.169$ & 0.537 & 18.37 \\
\hline \multicolumn{5}{|c|}{ Argetoaia-Dolj } \\
\hline 22 & A1 & $1.06 \pm 0.046$ & 0.146 & 13.832 \\
\hline 23 & A2 & $1.41 \pm 0.183$ & 0.578 & 41.17 \\
\hline 24 & A3 & $1.10 \pm 0.040$ & 0.127 & 11.59 \\
\hline
\end{tabular}

and $2.74 \mathrm{~g}$ (S4), showing a medium to very large variability, from $9.98 \%$ to $41.87 \%$ (Tab. 3). The differences between the values are due to differences in altitude of locations and climatic conditions. Other works indicate maximum values for this character up to $3.25 \mathrm{~g}$ in Transylvania (Roman et al., 2013), $6.1 \mathrm{~g}$ in Turkey (Kazankaya et al., 2005).

Recorded values for the mass of 100 fruits were between 117g (A1) and 286g (B3 and T4). In terms of percentage of pulp/fruit 100g, it ranged from $49.2 \%$ (M1) and 66.5\% (T1). The content of soluble dry solids (TSS) determined at harvest fruits ranged between 10-18\%. Vitamin C, the main biochemical component of rosehip fruit recorded values between 53 (B3) and 563 (S1 and S4) $\mathrm{mg} / 100 \mathrm{~g}$ fresh substances (Tab. 4).

Total acidity is an indicator that shows the presence of acids in fruit influencing the flavor. The populations studied recorded values between 1.4\% (B3) and 3.6\% (M4) (Tab. 4).

Other reports show pulp content between 40.47 and $79.98 \%$, vitamin C content varied from 301 to $1183 \mathrm{mg} / 100 \mathrm{~g}$ and TSS between 14.8 and $36.2 \%$ for fruits harvested in Turkey (Kazankaya et al., 2005).

In Romania, some studies indicate vitamin C content values between 447.37 and 573.2 $\mathrm{mg} / 100 \mathrm{~g}$ powder, fruits harvested from Danube Plain and Dobrudja (Ropciuc et al., 2013) and between 100 and $400 \mathrm{mg} / 100 \mathrm{~g}$ fresh matter for fruits harvested from Harghita and Neamt (Ghiorghiță et al., 2012).

\section{CONCLUSIONS}

High variability of Rosa canina studied characters becoming from spontaneous flora of Oltenia indicating possibilities of using this material in the works to improve the species. thus: -From technological point of view it remarked B3 population with $2.88 \mathrm{~cm}$ fruit length; T4 with $1.44 \mathrm{~cm}$ diameter fruit; S4 with $2.74 \mathrm{~g}$ fruit weight and T1 with $66.5 \%$ for the pulp percentage;

-From biochemical characters were noted the populations: M1 with 18\% for TSS; S1 and S3 with $563 \mathrm{mg} / 100 \mathrm{~g}$ fresh substances for vitamin C content and M4 with 3.6\% acidity.

Acknowledgment. This work was partially supported by the grant number 13C/27.01/2014 
Tab. 4. Average values of some technological and biochemical parameters on the rosehip populations

\begin{tabular}{|c|c|c|c|c|c|c|}
\hline No. & $\begin{array}{l}\text { Population/ } \\
\text { County }\end{array}$ & $\begin{array}{l}100 \text { fruit } \\
\text { mass (g) }\end{array}$ & $\begin{array}{c}\text { Pulp } \\
\text { percentage/ } \\
100 \mathrm{~g} \text { fruits }\end{array}$ & $\begin{array}{l}\text { TSS } \\
(\%)\end{array}$ & $\begin{array}{l}\text { Vitamin C } \\
\text { (mg/ } \\
100 \mathrm{~g} \mathrm{f.} \mathrm{m)}\end{array}$ & $\begin{array}{c}\text { Titrable } \\
\text { acidity } \\
(\%)\end{array}$ \\
\hline \multicolumn{7}{|c|}{ Carcea (Banu Maracine)-Dolj } \\
\hline 1 & $\mathrm{~B} 1$ & 210 & 60.5 & 17 & 88 & 1.5 \\
\hline 2 & $\mathrm{~B} 2$ & 179 & 54.7 & 10 & 75 & 1.6 \\
\hline 3 & B3 & 286 & 63.6 & 12 & 53 & 1.4 \\
\hline 4 & B4 & 134 & 52.9 & 17 & 106 & 1.9 \\
\hline 5 & B5 & 211 & 61.6 & 16 & 158 & 1.9 \\
\hline \multicolumn{7}{|c|}{ Simnic-Dolj } \\
\hline 6 & S1 & 257 & 54.8 & 17 & 563 & 1.7 \\
\hline 7 & $\mathrm{~S} 2$ & 265 & 59.2 & 14 & 493 & 1.6 \\
\hline 8 & S3 & 258 & 60.7 & 15 & 563 & 1.9 \\
\hline 9 & S4 & 269 & 60.2 & 16 & 493 & 1.7 \\
\hline 10 & S5 & 260 & 57.0 & 17 & 475 & 1.9 \\
\hline 11 & S6 & 216 & 59.9 & 15 & 334 & 1.9 \\
\hline 12 & S7 & 222 & 63.8 & 16 & 317 & 1.8 \\
\hline \multicolumn{7}{|c|}{ Morunglav-Olt } \\
\hline 13 & M1 & 134 & 49.2 & 18 & 387 & 3.5 \\
\hline 14 & M2 & 200 & 56.7 & 14 & 317 & 3.4 \\
\hline 15 & M3 & 132 & 50.7 & 17 & 370 & 3.5 \\
\hline 16 & M4 & 149 & 64.2 & 16 & 300 & 3.6 \\
\hline 17 & M5 & 160 & 52.6 & 16 & 264 & 3.5 \\
\hline \multicolumn{7}{|c|}{ Teslui -Olt } \\
\hline 18 & $\mathrm{~T} 1$ & 248 & 66.5 & 13 & 194 & 2.5 \\
\hline 19 & $\mathrm{~T} 2$ & 241 & 62.7 & 12 & 141 & 2.3 \\
\hline 20 & T3 & 217 & 57.6 & 14 & 211 & 2.4 \\
\hline 21 & $\mathrm{~T} 4$ & 286 & 58.2 & 14 & 173 & 2.6 \\
\hline \multicolumn{7}{|c|}{ Argetoaia-Dolj } \\
\hline 22 & A1 & 117 & 50.4 & 15 & 241 & 2.5 \\
\hline 23 & A2 & 152 & 53.1 & 13 & 194 & 2.5 \\
\hline 24 & A3 & 118 & 53.6 & 14 & 176 & 2.4 \\
\hline
\end{tabular}

awarded in the internal grant competition of the University of Craiova".

\section{REFERENCE}

1. Botu I, Botu M (2010). Experimental techniques in horticulture and ecology. Basics Elements .

2. Celik F, Kazankaya A, Ercisli S (2009). Fruit characteristics of some selected promising rosehip (Rosa spp.) genotypes from Van region of Turkey. African Journal of Agricultural Research 4 (3):236-240.

3. Demir F, Özcan M (2001). Chemical and technological properties of rose (Rosa canina L.) fruits grown wild in Turkey. Journal of Food Engineering 47(4):333-336.

4. Gaik MK (2011). Bioactive plant foods. PhD Dissertation Gaik Ming Khoo. Faculty of Agricultural Sciences. Aarhus University 116 p.

5. Ghiorghiță G, Antohe N, Rați IV, Maftei DE (2012). The study of some parameters of Rosa canina L. genotypes from different native populations and from the same population. Annals of the University „Al. I. Cuza” Iași. Plant Biology 58 (1): 19-27.
6. Güneș M (2010). Pomological and phenological characteristics of promising rose hip (Rosa) genotypes .African Journal of Biotechnology 9(38):6301-6306.

7. Haas LF (1995). Dog rose (Rosa canina). J. Neurol. Neurosurg. Psychiatry 59(5):470.

8. Kaack K, Kuhn BF (1991). Evaluation of rose hip species for processing of jam jelly and soup. In: Tidsskr. Planteavl 95:353-358.

9. Kazankaya A, Turkoglu N, Yilmaz M, Balta MF (2005). Pomological description of Rosa canina selections from Eastern Anatolia. Turkey. Intrenational Journal of Botany 1(1):100-102.

10. Kazaz S, Baydar H, Erbas S (2009). Variations in chemical compositions of Rosa damascena Mill. and Rosa canina L. fruits. Czech J. Food Sci. 27:178-184.

11. Mabellini M, Ohaco E, Ochoa MR, Kesseler AG, Márquez CA, De Michelis A (2011). Chemical and physical characteristics of several wild rose species used as foodor food ingredient. International Journal of Industrial Chemistry 2(3): 158-171.

12. Nețoiu C, Visoiu D, Bădele $O$ (2008). Dendrology 
13. Özcan M (2002). Nutrient Composition of Rose (Rosa canina L.) Seed and Oils Journal of Medicinal Food 5(3):137-140.

14. Roman I, Holonec L (2012). Strategy of Establishing a Rosehip Plantation Using Varieties of Rosa Canina from Spontaneous Flora of Transylvania. Bulletin UASVM Horticulture. 69(1):424.

15. Roman I, Stănilă A, Stănilă S (2013). Bioactive compounds and antioxidant activity of Rosa canina L. biotypes from spontaneous flora of Transylvania. Chemistry Central Journal 7:73.

16. Ropciuc S, Leahu A, Crețescu I (2013). The influence of solar radiation on the vitamin $\mathrm{C}$ content in Rosa canina fruits. Romanian Biotechnological Letters 18 (1):80268033

17. Şerban D (2011). Marc fresh rosehip. http:// agroromania manager.ro/ Accesed by 06.02.2014.
18. Sharafi Y (2010). Biological characteristics of pollens in some genotypes of Rosa canina as main factors affecting fruit set. Journal of Medicinal Plants Research 4 (20): 2173-2175.

19. Shirdel M, Motallebi-Azar A, Matloobi M, Zaare-Nahandi F (2013). Effects of noodal position and growth regulators on in vitro growth of dog rose (Rosa canina). Journal of Ornamental and Horticultural Plants 3 (1): 9-17.

20. Soare R, Iancu P, Soare M, Bonea D, Manila G, Panita O (2014). Morfological and biochemical issues to some Rosa canina L. populations from the spontaneous flora from SoutWest Romania. Micro and Nano Tehnologies advances in biotechnology 1:432-442.

21. Wagner S (2002). Rose from myth to the third millennium. 